\title{
Activity and learning contexts in educational transmedia
}

\author{
Núria Molas Castells \\ nmolascastells@ub.edu \\ Universitat de Barcelona, Spain \\ José Luis Rodríguez Illera \\ jlrodriguez@ub.edu \\ Universitat de Barcelona, Spain
}

\begin{abstract}
The idea of transmedial organisation emerged as the form adopted by much of today's storytelling, combining different media, at different points in time, placing the user in a new situation with a much more active attitude, having to work out how to understand a set of message and having to engage in the understanding of the story (Jenkins, 2006). Transmediality has some educational consequences that set it apart from other approaches, even outside specific learning contexts. Some of the ideas discussed led to the creation of a project entitled The Ancestral Letter, a transmedia story, designed and produced specifically for 15-year-old students. The project was implemented in two secondary schools in Barcelona in order to verify the interest in this concept. The journey we have made, from a few starting principles and theoretical problems to a complex case of transmedia storytelling, clearly highlights the difficulty involved in addressing the question of learning between contexts, and through them, especially if it is carried out in a simple and simplified manner; that is, without having a much more elaborate theory of learning contexts, nor a rigorously designed descriptive language. The Ancestral Letter and other transmedia examples offer us a more understandable and effective way of coordinating between the school-based and informal settings, between the digital setting and everyday life (analogical, not mediated by screens), both in terms of the organisation of content and in respect of time-based narrative. Unfortunately, we still do not have enough knowledge about this or about activity contexts (whether or not learning takes place within them).
\end{abstract}

\section{Keywords}

Transmedia storytelling; learning contexts 


\section{Theoretical framework}

1. The very idea that one learns in different contexts or through them implies different contexts of activity and learning, which may be distinguished, classified and characterised as similar or distinct. Although the terminology and nuances are different (places, scenarios, situations), the distinction, classification and functions of contexts still constitute an important, open question that addresses their structure, the shift from certain contexts to others, the social determinations they reflect, the different technologies they encapsulate and the personal journey that takes place, along with the forms of learning and the type of knowledge that is constructed (some examples of analysis can be found in Bliss, Säljö \& Light, 1999; Ludvigsen, Lund, Rasmussen \& Säljö, 2011; Erstad et al, 2016). In other words, a set of unresolved questions exists that is too broad to be dealt with in one or several brief answers.

There are several observations to be made regarding this way of setting out a problem, particularly in respect of how these contexts are characterised, both internally and in terms of the relationship between them. We will return to this issue later on. For now, we would like to discuss and focus on a particular response to the general problem of how the proliferation of digital media has led to a rethinking of some of these questions, as well as generating new questions in the educational sphere.

Following a line of thinking tightly bound up with technology, with its changes and developments, the novelty of person-machine interaction, forms of immediate feedback or the encapsulation of knowledge in "expert" systems have constituted milestones in this approach, albeit conditioned by the limitations intrinsic to emerging, unrefined technology. Without a doubt, the arrival of multimedia applications, highlighting the metamedial nature of the computer screen, and the recognition of the "multimodal" potential of computers and screens, have also supposed a definitive broadening of its scope, despite its limitations and criticism (Rodríguez Illera, 2004). Ultimately, the idea of transmedial organisation emerged as the form adopted by much of today's storytelling, combining different media, at different points in time, placing the user in a new situation with a much more active attitude, having to work out how to understand a set of message and having to engage in the understanding of the story (Jenkins, 2006).

Although the novelty of the terms may be ephemeral, transmediality has become something of a paradigm of the post-modern functioning of the media (including digital ones, of course) in a fairly substantial number of areas of communication, entertainment and advertising. The princeps example that Jenkins focused on to analyse transmedia storytelling was The Matrix franchise. Later on (Jenkins, 2009), its use was extended to education, under a kind of implicit slogan: education is transmedial (as before it was multimodal, participatory or interactive).

Nevertheless, media are not contexts; neither do they have such a large presence in our direct experience, unmediated by screens, which constitutes a high percentage of our daily lives and face-to-face social interaction. In fact, there are specialised contexts designed for teaching and learning, along with other more spontaneous, non-designed contexts that also have educational effects. Transmediality is an organisational characteristic of media that affects learning contexts and what occurs within them. As such, it is necessary to bear in mind that it is not the only factor, or even the most decisive one in all likelihood.

2. Transmediality has some educational consequences that set it apart from other approaches, even outside specific learning contexts. Firstly, as we have already said, the almost excessive emphasis on media: although these media do not constitute contexts, 
some contexts seem to exist solely to support the media that create them, as seems to be the case with digital media in particular. Set against this "technologized" vision of learning, what we find within a context is always much more than media, as a result of the activity carried out within the context, whether direct or mediated (that is; with or without the media), and due to the cultural and social background of the context. It is true that media contribute to creating the codes of meaning and interpretation of messages and their hierarchy (as pointed out by Saitó, 2002: it is sufficient to see a few frames in order to know which audio-visual genre a message belongs to, and even the exact work) but messages are not produced or read in isolation from wider contexts that ultimately give them meaning. It is an encyclopaedic competence, in Eco's sense of the term, which goes beyond the literal independent meaning (if such a meaning even exists, as Sandvox questions - 2007) and which is always of a cultural nature: media are not universal, although some content is globalised for certain generations, but they do have a similar modus operandi.

Secondly, transmediality, or rather transcontextuality, can be developed in time and not only in space. It is true that time and space evoke the somewhat ingenuous (or spontaneous) conception of time and space as perceived in our daily lives. However, despite this intuitive use, "transmedialisation" (turning a message or complete story into a transmedial structure) involves being able to complete some of these messages at different points in time. We are not referring here to the "serialisation" of content (nor to media which by their very nature unfold over time), such as the first television series, or films split into several parts, including The Godfather or Kill Bill, but rather to those in which part of the content occurs or is distributed at a later point in time, by design, through media other than the original one (as occurs in The Matrix or in Star Wars).

This new approach to time is complementary and added onto the initial organisation of the original message/content, possibly altering its meaning. The most traditional education model sees education as a work, in the sense intended by Barthes (2002); that is, as something closed and complete whose meaning and original intention can only attributed to its author. However, education in the digital era is more like a text that is open to interpretations and additions, both by its author and by its readers, evolving over time, through hypertextual, multimedial and transmedial connections (if we focus more on the media than on the textual and narrative core).

Thirdly, the textual, open and time-based nature of transmedial organisation supposes that the comprehension of messages and that of their activity and learning contexts is an additive comprehension (Jenkins, 2006); that is, the meaning is reconfigured, to a greater or lesser extent, at each subsequent moment or point in time when a new medium and context appear. This is clearly something that also occurs in our daily lives, but in the case of transmedia it is an environment that organises different contexts and messages in an intentional manner, planning (totally or partially) the moment in which they appear and the degree of freedom and innovation that users may have.

Many of the ideas that attempt to coordinate formal education and parts of informal education, such as the so-called orchestration, aimed at teachers' work, have a similar aim, although unlike transmedia they do not emphasise the time dimension. In general, these attempts at coordination, whether formally organised or occurring spontaneously outside the school setting, must solve several problems, including the general problem of how different types of meaning are structured in different contexts and how they are integrated by the learner. It seems insufficient to classify them all as seamless learning (Zhang \& Looi, 2011), consisting of a perfect and straightforward integration between contexts, not even in the case of mobile-assisted learning, especially when contexts may be not only formal or informal but also digital, everyday and non-digital, or everyday with digital integration. 
Perhaps one of the keys to understanding when this integration between contexts occurs is the very nature of educational knowledge. Bernstein (1999) and Moss (2001), among others, have correctly argued that the separation of school-based and formal learning, on the one hand, and, on the other hand, the learning that occurs in everyday life (not other types of informal learning, such as in the workplace), is the connected, structured and hierarchical nature of the former, according to a model largely based on scientific knowledge. Although informal contexts are a recurring theme in pedagogical thinking and many nuances have been incorporated in this starkly dichotomic vision, the structuring capacity of school-based knowledge makes it suitable for taking on board other non-formal and informal activity and learning contexts.

Without a doubt, digital media have contributed to weakening the separation between forms of knowledge and between the categories that underpin this separation. Durkheim and Mauss (1963) showed us that forms of classification are based on separate categories, such as the formal and the informal, or the pure and the impure (Douglas, 1966), which enables us to make distinctions and think in real or symbolic terms. Meanwhile, Bernstein (1971) further explores this idea through his own notion of classification, focusing on the power of separation between the boundaries of knowledge: a strong classification keeps categories separate (for example, the very concept of a "subject"), while a weak one blurs the boundaries and allows categories and principles (such as project-based work or the multifunctional use of school spaces) to merge. Accordingly, a strong classification between contexts keeps them separate (in real and symbolic terms) and makes it more difficult to learn through them in an integrated manner.

A second key to understanding this transmedial integration, especially when it does not involve educational "knowledge" or scientific knowledge, but rather information-based or persuasive messages, is the narrative form they adopt, or the broader category in which they can be classified, which gives a more general sense to the variations of meaning and understanding that are generated in and between the different contexts of activity and learning. This can be clearly seen when the contexts include games, digital games, consumption of/participation in media (such as novels and fan fiction, films, television, comics, Japanese anime or manga) and creation of digital content (vids, machinima, remixes), but also when one of the contexts is simply "traditional" (non-digital) and interacts with others, or when content from two or more contexts merges (such as in crossover fan fiction).

However, when the dispersion of transmedia elements over time takes place in intentional contexts, it runs parallel to that which occurs spontaneously in everyday life: in both cases, narrative integration is what ensures that the created meaning can be additive (Schank, $1990,1999)$. The idea of narration used here is somewhat different from the usual one, which often identifies narration with the act of narrating itself, as in the case of oral and written stories. Narrative discourse is understood here in the sense intended by Genette (1982); that is, as a logical chain of actions (in the style of authors such as Propp, Greimas, Ricoeur or Brémond, among others) in which what occurs at a later moment in time (of the time external to the narration) may have effects on the "internal" or diegetic time of the story itself. Therefore, both in narratology and in models of mental functioning, the time concerned with everyday life, always and only as a "forward" flow, operates in tandem with the "mental" time or narrative; that is, the time in which the meaning of actions and facts is internally constructed.

Transmedia storytelling, or one of its variants (Dena, 2011; Ryan \& Thon, 2015) may serve as a model, still to be perfected, in order to understand the immense variability that exists between the digital world, with its almost infinite forms, and non-digital everyday life 
(equally limitless, despite its cyclical and repetitive nature), or between the formal and informal relations of education. The two universes constantly merge and reappear over time, with new media and messages, in different contexts, requiring a common narrative discourse in order to facilitate their integration. The fact is that, by definition, it always has a weak classification, both between contexts and within each one, but this probably stems from its origins in the sphere of fiction. In the educational sphere, things are slightly different and require more precision and care, but we can theoretically take advantage of the integrating sense of the idea of storytelling; that is, the idea of organising different media, messages and context-based activities within a common story that gives meaning to each of its constituent parts. We can also exploit the transmedial and time-based nature of transmediality.

\section{An example: The Ancestral Letter}

Some of the ideas discussed above, together with the desire to experience this new approach, led to the creation of a project entitled The Ancestral Letter, a transmedia story similar to an ARG (Alternative Reality Game), designed and produced specifically for 15year-old students. The project was implemented in two secondary schools in Barcelona in order to verify the interest in this concept.

All the materials that make up The Ancestral Letter were specifically designed and chosen in order to make a meaningful contribution to the narrative and to facilitate access to the various parts of the story. Within the map of the narrative world, the timing and the contribution of the different media were designed beforehand, allowing enough flexibility to facilitate the students' participation. In total, more than ten different materials were designed and produced specifically for The Ancestral Letter, on the basis of preparatory work carried out with the teaching staff in order to incorporate the aspects of the curriculum that could be integrated in a coherent manner with the plot, along with the follow-up and evaluation tools.

The plot of The Ancestral Letter is based on the mystery of a parchment, owned by the Ancestrals, a secret community which, in order to protect the equilibrium of the Earth, decides to rid it of human beings, thus removing those responsible for the destruction of the planet. The Ancestrals' plans involve gradually replacing human beings with androids. In the testing phase we meet Toni, an android prototype given the mission of fully integrating in society. Toni's integration is so successful that he ends up developing human emotions. The Ancestrals, led by Estrella Blanco, decide to deactivate the prototype. Toni manages to escape and, from his hideout, asks for help to discover the alphabet of the parchment in order to prevent his deactivation. To unravel the mystery of the parchment, students must uncover the clues and information provided through analogical materials, such as a personal diary, but also through digital tools, such as a webquest, a treasure hunt and a blog, among others (a detailed description can be found in Molas-Castells, 2017).

The Ancestral Letter was incorporated and initiated in the two secondary schools in the form of a video letter that called on participants to engage in the unfolding plot in order to obtain information and thus help the protagonist. The students actively participated in gathering information, creating meanings and possible "paratexts", progressing through the story all the way through to the ending. The various activities were carried out both within and outside the school setting. The school's own materials were used, along with tools not habitually used in formal education. 


\section{Methodology}

The main goal of the empirical study is the systematic analysis of the implementation of The Ancestral Letter, focusing on the pedagogical benefits that may be gained from it. From the perspective of its potential educational interest, the most noteworthy possibilities include the structuring of a proposal that makes it possible to put into practice decoding skills and to create and bring into play different media content through a narrative world based on multiple media and in which student participation was the essential core element.

The observational work focused on the practices of the students that enabled the generation of new environments and different journeys for each person, with the goal of describing and understanding the practices generated by the proposed transmedia story. An analysis was made of the students' activities and experience in their relationship with the story and beyond the contextual boundaries. This shift from one situation to another is framed and gains meaning, as discussed above, from a perspective that considers that the boundaries and relations between contexts must be broadened, rethought and increasingly blurred.

The method used in the research is the multiple case study, in line with Stake's approach (1998), which includes the study of more than one case with the objective of researching a certain phenomenon, in this case The Ancestral Letter. The sample was a group of students in the fourth year of compulsory secondary education (15 years old) from two different secondary schools in the province of Barcelona. The two case studies had features in common related to their geographical area, socio-economic characteristics, school size and available infrastructure. There were 165 participants in total: 161 students and 4 teachers.

Information was gathered both during and after the implementation stage. During the implementation stage, the following instruments were used: a session diary drawn up by the teaching staff, a field diary produced by the researchers and a review of the students' artefacts, productions and participation in networks. Following the implementation stage, indepth interviews of the students and teaching staff were conducted. A total of 40 interviews were conducted ( 16 for the first case study and 24 for the second one), distributed according to the students' level of participation.

The analysis process was carried out by classifying the data according to the basic units of meaning, adopting an open character, in which the data was analysed using categories which were inferred from the theoretical information but which could be adapted as necessary over the course of the process. The first interpretation stage involved coding (segmentation and hierarchical classification of the text), while the second stage involved categorisation; that is, the simplification of the content according to thematic criteria.

\section{Results and analysis}

The interventions of the media that comprise The Ancestral Letter were strategically planned to contribute to the students' immersion in a coherent and plausible narrative world and to facilitate their collective understanding of it, on the basis of three interweaving storylines. The comprehension of the story was necessarily additive (Jenkins, 2006), in such a way that each medium provided a new piece of information that students had to decode and connect to the previous pieces of information. In other words, the gradual development of the narrative world did not depend on a single medium but rather on its coordinated whole.

1) In the decoding and interpretation of the pieces of information, the construction of 
meanings was characterised in The Ancestral Letter by the convergence of media and languages, which facilitated multimedia communications based on the use of a variety of materials and platforms. Students were explicitly tasked from the beginning with bringing together the many pieces of information, as can be observed in the conducted interviews. The construction of meanings was facilitated through a certain amount of thematic specialisation but also through the technical expertise of students, making specific use of some of the tools.

The mobility-enabling tools played a noteworthy role, facilitating the students' perception that the practices were being carried out across their different life settings and not in an isolated manner. Many of the tasks generated by The Ancestral Letter began in the classroom and continued in other spaces and settings. In this respect, practices such as the use of Facebook, associated more with leisure time, were incorporated in the school-based work as a tool for dialogue and debate. As one of the teachers explains, "They've taken the story home in order to continue their investigations or to share it with the family and with other friends. The fact that they're taking work home or bringing it to school without being asked is one of the most interesting aspects of this project. Succeeding in transferring the story to all the areas of their lives is something which we teachers are not often capable of doing."

2) The construction of meanings could begin on completion of the initial stage, which comprised putting the pieces together, decoding the messages and incorporating them in the narrative world. The second stage involved the creation of hypotheses. Taking the data gathered through the narrative instruments, it was possible to differentiate between the process of the construction of meaning and that of the creation of hypotheses, related to the degree of engagement of the students. In the first case study, unlike in the second one, options were created and collectively negotiated in order to make progress in understanding the story. For example, as one of the interviewed students explained, "We talked about all the things we discovered individually. At breaktime we got together and talked about everything; us and all the people in the other classes."

In the relations that the students themselves established between practices and their contexts, differences were observed between practices that were associated with formal contexts and those traditionally related to other informal or non-intentional settings. Negotiation processes took place regarding meanings closely related to the context and arising both from the formal system of the story and, in particular, from its relationship and interference with the students' real world. They made decisions and took positions on the basis of their real conventions. The students stated that they had very little or no previous experience in transferring skills or competences that they associate with different settings. In this respect, as discussed in the theoretical framework, the interpretation that the students made according to the context was determined by the activity carried out and, above all, by their cultural and social background, conventions, purposes and even the behaviours that they associated with the specific context. As such, they stated in their interviews that their interpretation of processes, their relations and even the value they gave to practices was different according to the context with which they associated them. Furthermore, there was a certain amount of difference between the generated expectations, the conventions or even the rewards they expected to receive according to whether they situated the activity in specific contexts, whether one designed for an educational purpose or more spontaneous or everyday contexts. The identification of differences between contexts is a physical question but is also related to a background that has altered the putting into practice of different strategies. When the practices were associated with a formal context, exceptional knowledge domains emerged and significant importance was attached to the evaluation. Meanwhile, when they situated the activity in a less institutionalised setting, vernacular practices that 
exist in more everyday domains became visible.

One of the characteristics that define transmedia storytelling is the active participation of users, both in the interpretative process of the story, which is closely related to the context, and in the expansion of the story. The design and planning of The Ancestral Letter offered users the chance to explore different possibilities, to elaborate and check hypotheses, and to emphasise their active role. On the basis of the reading work completed by the students, some productions were carried out that made it possible to broaden and, to a certain extent, modify the development of the story.

The artefacts produced by the students were:

\begin{tabular}{|l|l|}
\hline Productions & $\begin{array}{l}\text { Total } \\
\text { no. }\end{array}$ \\
\hline Treasure hunt & 9 \\
\hline Postcard & 20 \\
\hline Short story & 15 \\
\hline Active profiles on Facebook & 81 \\
\hline Email profiles & 18 \\
\hline Blog posts & 81 \\
\hline Webquest & 37 \\
\hline
\end{tabular}

Table 1. Productions made by students Source:

The productions carried out include both those explicitly required as the story unfolded and other productions (although somewhat token efforts) that went beyond the pre-designed spaces of participation. The actions that were not pre-established are the consequence of the investigative and decision-making process of the students. However, despite the students' willingness, in both case studies their lack of previous experience in the role of producers was evident. In case study 1 , in which there was a tradition of project-based work, students found it more straightforward to put previous knowledge and strategies into practice. Nevertheless, the lack of prior instructions generated some uncertainty or a certain lack of direction when it came to guiding and organising their activity. Much work clearly remains to be done in respect of fostering the students' active role in order to broaden and emphasis their role as producers, putting into practice curriculum-based competences and skills but also, and above all, those which are developed in leisure time settings and which tend to be undervalued in formal contexts.

\section{Conclusions and discussion}

The journey we have made, from a few starting principles and theoretical problems to a complex case of transmedia storytelling, clearly highlights the difficulty involved in addressing the question of learning between contexts, and through them, especially if it is carried out in a simple and simplified manner; that is, without having a much more elaborate theory of learning contexts, nor a rigorously designed descriptive language. Excellent work has been done, such as the review by Nardi (1998) on textual theories, or that of Eichner (2013) on media reception and creation of agencies (identities) in this reception process, or 
the research by Bronkhorst and Akkerman (2016), who introduce the distinction between continuity and discontinuity in respect of school-based and non-school-based learning in order to review a wide selection of studies on learning through formal and non-formal contexts, in an attempt to find out why continuity or discontinuity occurs, with some interesting results.

Generally speaking, these approaches set a formal and familiar context with explicit rules (such as a school) against another context which, while not formal, also has explicit rules, or against the consumption and participation in media and games in everyday life, with implicit rules, or a mixture of both (Vygotsky, 1979, in relation to child's play, types of rules, and their relationship with development). It is difficult to situate the contexts or imaginary situations created in games or in fiction, not only due to how they evolve but also due to the complex forms they adopt in the digital world, such as ARG, role games, virtual reality, pervasive games and, of course, transmedia storytelling. They probably all involve a quest, solving a problem or answering a question, but most of them follow an almost exclusively digital logic that does not seem to be appropriate for the case of education.

The Ancestral Letter and other transmedia examples offer us a more understandable and effective way of coordinating between the school-based and informal settings, between the digital setting and everyday life (analogical, not mediated by screens), both in terms of the organisation of content and in respect of time-based narrative. Unfortunately, we still do not have enough knowledge about this or about activity contexts (whether or not learning takes place within them). A long-term research programme therefore seems necessary.

\section{References}

Barthes, R. (2002). De I'oeuvre au texte. In R. Barthes: Oeuvres Complètes, vol. III, 19681971. Paris: Seuil, [1971], pp. 908-916.

Bernstein, B. (1971). On the classification and framing of educational knowledge. En B. Bernstein: Class, codes and control, vol. 3. London: Routledge, 85-115.

Bernstein, B. (1999). Vertical and Horizontal Discourse: an essay. British Journal of Sociology of Education, Vol. 20, 2, 157-173.

Bliss, J., Säljö, R. \& Light, P. (eds, 1999). Learning Sites. Social and Technological Resources for Learning. London: Pergamon.

Bronkhorst, L.H. \& Akkerman, S. F. (2016). At the boundary of school: Continuity and discontinuity in learning across contexts. Educational Research Review, vol. 19, November 2016, 18-35.

Dena, C. (2011). Do you have a big stick?. In: if: book Australia [https://www.futureofthebook.org.au/news/2011/02/do-you-have-a-bigstick?rq=do\%20you\%20have $\% 20 a \% 20$ big $\% 20$ stick]

Douglas, M. (2002). Pureza y peligro. Un análisis de los conceptos de contaminación y tabú. Madrid: Siglo XXI [original: 1966]

Durkheim, E. \& Mauss, M. (1963). Primitive Classification. London: Cohen \& West, [1903].

Eco, U. (1975). Tratado de semiótica general. Barcelona: Lumen.

Eichner, S. (2014). Agency and Media Reception: Experiencing Video Games, Film, and Television. Berlin: Springer.

Erstad, O. et al. (Eds, 2016). Learning across Contexts in the Knowledge Society. Rotterdam: Sense Publishers.

Genette, G. (1982). Récit du discours. Paris: Seuil [1971] 
Jenkins, H. (2006). Convergence culture where old and new media collide. New York: New York University Press.

Jenkins, H. (2010). Transmedia Education: the 7 Principles Revisited. http://henryjenkins.org/blog/2010/06/transmedia_education_the_7_pri.html

Ludvigsen, S., Lund, A., Rasmussen, I. \& Säljö, R. (Eds, 2011). Learning Across Sites. New tools, infrastructures and practices. London: Routledge.

Molas Castells, N. (2017). La narrativa transmèdia a l'educació. Doctoral Disseration, University of Barcelona.

Moss, G. (2001). On Literacy and the Social Organisation of Knowledge Inside and Outside School. Language and Education, 15, 2-3, 146-161.

Nardi, B. (1996). Studying Context: A Comparison of Activity Theory, Situated Action Models, and Distributed Cognition. En B. Nardi (ed): Context and Consciousness. Cambridge (MA): MIT Press, p.69-102.

Rodríguez Illera, J.L. (2004). Multimedia learning in a digital world. In Brown, A. \& Davis, N. (eds) World Yearbook of Education 2004. Digital technology, communities and education. London: Routledge Farmer, p. 46-56.

Ryan, M.L. \& Thon, J.N. (eds, 2014). Storyworlds across Media. Lincoln: University of Nebraska Press.

Saitó, T. (2011). Beautiful Fighting Girl. Minneapolis: University of Minnesota Press.

Sandvoss, C. (2007). The Death of the Reader? Literary Theory and the Study of Texts in Popular Culture. In: J. Gray, C. Sandvoss \& C.L. Harrington. (eds) Fandom. Identities and Communities in a Mediated World. New York: New York University Press. p. 19-32.

Schank, R.C. (1990). Tell me a story: Narrative and intelligence. Evanston, IL: Northwestern University Press.

Schank, R.C. (1999). Dynamic memory revisited. Cambridge: Cambridge University Press.

Tuomi-Gröhn, T. \& Engeström, Y. (eds, 2003). Between School and Work. New Perspectives on Transfer and Boundary-crossing. Oxford: Pergamon.

Vygotski, L.S. (1979). El desarrollo de los procesos psicológicos superiores. Barcelona: Crítica.

Zhang, B.H. \& Looi C. K. (2011). Developing a sustainable education innovation for seamless learning. Procedia Social and Behavioral Sciences, 15 (2011) 2148-2154. 